\title{
Thoracic outlet syndrome
}

INSERM

\section{Source}

INSERM. (1999). Orphanet: an online rare disease and orphan drug data base. Thoracic outlet syndrome. ORPHA:97330

Thoracic outlet syndrome (TOS) is a group of disorders characterized by paresthesias, pain and weakness of the upper extremities due to compression, tension or inflammation of the neurovascular bundle as it passes through the thoracic outlet. There are 3 forms of TOS with different clinical pictures and etiologies: neurog enic TOS (NTOS) that can be divided into true or disputed forms, arterial TOS (AT OS) and venous TOS (VT OS) (see these terms). 